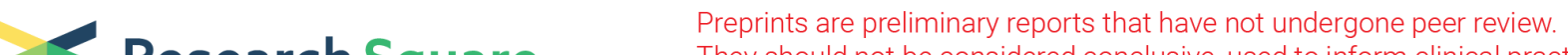 Research Square They should not be considered conclusive, used to inform clinical practice, or referenced by the media as validated information.
}

\section{A Questionnaire-Based Assessment of Functional Dry Eye Disease in Working-class Population in Shanghai, China}

\author{
Nianhong Wang \\ Huashan Hospital Fudan University \\ Dan Chen \\ Huashan Hospital Fudan University \\ Yan Liu \\ Huashan Hospital Fudan University \\ Huan Weng \\ Huashan Hospital Fudan University \\ Huiying Wang \\ Huashan Hospital Fudan University \\ Weibao Xiao ( $\nabla$ explorer_shaw@163.com ) \\ Fudan University
}

\section{Research article}

Keywords: Functional dry eye disease (Functional DED), Working-classes, Risk factors, Questionnaire

Posted Date: April 3rd, 2021

DOI: https://doi.org/10.21203/rs.3.rs-380033/v1

License: (c) (i) This work is licensed under a Creative Commons Attribution 4.0 International License. Read Full License 


\section{Abstract \\ Background}

To investigate the current status, morbidity, and risk factors of functional dry eye disease (DED) in Shanghai's working-class population. On this basis, exploring measures and methods to fundamentally cure and prevent functional DED.

\section{Methods}

A questionnaire form was used to record the data of the diagnosed functional DED working-class subjects in Shanghai, the results were recorded and analyzed. Additionally, the subjective symptoms of DED subjects and the respective clinical results were also recorded. The classification and corneal staining between subjects who wear contact lens or without were compared. The correlation of classification and corneal staining with their risk factors were also analyzed.

\section{Results}

The risk factors of functional DED showed much in common though their works have professional particularity. EDE accounts for a large proportion of DED (45.35\%), many subjects coexist symptoms and signs of mixed DED (32.64\%). The age of $21-40$ is the peak year range (70.4\%). Contact lens, visual terminals, air-conditioner, decoration, stay up later, sleep disorder, smoking were risk factors in most functional DED subjects. Notably, contact lens is a leading risk factor to cause functional DED and ocular surface complications (both were $p<$ $0.01)$, while deep sleep seems to be a protective factor $(p<0.01 \%)$.

\section{Conclusion}

The incidence of functional DED in Shanghai is kept in a high level, most risk factors are closely related to daily work and life, while they are almost reversible. Exploring and eradicating these daily risk factors seems to be a more preferable way to fundamentally control and prevent functional DED.

\section{Background}

Dry eye disease (DED) is a multifactorial disease of the ocular surface characterized by a loss of homeostasis of the tear film, and accompanied by ocular symptoms, in which tear film instability and hyperosmolarity, ocular surface inflammation and damage, and neurosensory abnormalities play etiological roles [1]. According to international statistics in 2007, the incidence of dry eye in Europe and America is 5.5\% - 15\%, while in Asia, the incidence is as high as $27 \%-34 \%$ [2]. These findings have been confirmed by the latest clinical epidemiological reports of large-scale DED patients in European and Asian countries [3, 4]. According to a recent 10 year investigation, DED symptoms have not been effectively treated, discomfort and visual disturbance of patients' eyes have been continuously aggravated, which significantly affect their daily work and lives [5]. Similarly in Shanghai, a metropolis in China, DED is becoming a more and more prevalent problem for the working-class. In Shanghai, the work rhythm is increasingly fast, with a life stress more and more suffocating. Mobile phones, 
computers and other electronic tools have become indispensable with daily activities. In addition, the polluted environment, closed work and living quarters, frequent overtime work, poor sleep habits, and insomnia all likely contribute to a sub-optimal health state of the eye, which may lead to deteriorated composition and contents of tear film, resulting in low quality or quantity of tear film and high incidence of DED.

According to the etiological and pathogenetic classification, DED can be divided into aqueous deficient dry eye (ADDE) and evaporative dry eye (EDE). ADDE describes conditions affecting lacrimal gland function. While EDE is recognized to include both lid-related and ocular surface-related causes. ADDE includes the Sjogren syndrome (SS) and non-SS. EDE derives from intrinsic factors, such as eyelid and meibomian gland dysfunction, and extrinsic factors including vitamin A, contact lens, drug preservative, etc [1]. It is worth noting that in 2019, Liang et al described the concept of functional DED, namely, patients with dry eye symptoms but without detectable signs [6]. Similarly, based on clinical treatment effect and prognosis, DED can also be divided into reversible or curable and incurable or only alleviated classifications. Generally, the former has no obvious primary pathological signs and, namely, the functional DED, while the latter is organic DED, often caused by certain and irreversible primary diseases such as rheumatism, immune diseases, drugs, surgery, etc. We believe that this classification might have advantages in better practicality in clinical observation and treatment. In our clinical work, we found that most of DED patients actually belong to functional DED subtypes, with no primary disease and no irreversible tissue or organ damage. For these functional DED patients, if we can trace and confirm the pathogenic factors, and effectively minimize or eliminate these risk factors, these functional DED patients can be cured from the source level, and surely the effect is ideal and lasting.

In view of this, we enrolled 527 functional DED patients, they were all young to middle-age, working-class population, representing practitioners in various industries in Shanghai. We conducted a survey in the form of questionnaire, aiming at exploring the inducing factors of functional DED. Furthermore, we also conducted an additional study by combining the survey data with the observations of clinical examinations. Our results show that the incidence of functional DED is high among the working-class in Shanghai. Most functional DED are associated with inducing factors from their ordinary work and life. Contact lens may be a leading risk factor of functional DED, while good sleep hygiene seems to be a protective factor. It should be noted that, from the perspective of our long-term clinical observation, as long as these risk factors were identified and eradicated, functional DED was significantly alleviated or even cured.

\section{Methods}

In this study, we only focused on the working-class who lived and worked in Shanghai. These patients were all diagnosed in our hospital as functional dry eye patients. The study adhered to the tenets of the Declaration of Helsinki. All participants gave informed consent. A power analysis was performed to determine the number of patients that needed to be enrolled in the study. The specific methods are as follows:

\section{Enrolled patients}

527 patients with diagnosed functional DED were surveyed in this study. The selected objects were office workers people who worked and lived within the metropolitan area of Shanghai. The scope covers those who worked and served in various industries in Shanghai, without obvious primary or organic diseases.

Functional DED enrolled standards: 1. Dry eye symptoms: dry discomfort, photophobia, gritty sense, etc. 2. Tear break-up test: $<10$ seconds. 3. Tear film curvature radius: $<0.5 \mathrm{~mm}$. 4. Positive corneal staining. 5 . Abnormal 
morphology or opening of meibomian gland. 6. Elevated tear film osmolality. The symptoms plus above two or more positive examination results were considered as the DED inclusion criteria. Exclusion criteria: 1. Diabetes, 2. Sjogren's syndrome. 3. Ankylosing spondylitis. 4. Laser myopia or keratoplasty. 5. Ocular surface active inflammation. 6. Cataract surgery and 7. Other known diseases or drugs causing dry eye.

\section{Questionnaire survey}

The main purpose of this survey is to explore by questionnaire form the working-class with diagnosed functional DED, who worked and lived in Shanghai. The enrolled patients' age, gender, work and education background reflect the general characteristics of this population in Shanghai. The questionnaire comprehensively investigated their work and life habits, especially those related to the use of electronic screens (mobile phone, computer, TV), daily life, working environment, contact lens, and others. The results were recorded and analyzed.

\section{Observation of clinical symptoms and signs}

When collecting the data by questionnaire, we also recorded the subjective symptoms of every DED patient and the respective examination results by clinical means. These results mainly include the types of DED, ocular surface damage by contact lens, corneal fluorescein staining, etc. By collecting these clinical data, we investigated the characteristics of functional DED, and compared the differences in symptoms and signs of ocular surface damage caused by various factors. Based on this, by combining with the results of the questionnaire data, we aim to explore the underlying causes of this disorder.

\section{Statistical analysis}

Statistical analysis was carried out using IBM SPSS software version 22.0 version. The data were expressed as mean or mean \pm standard errors. Frequencies were compared between functional DED patients wearing contact lens group and other functional DED patients group, and DED classification percentage using a chi-squared test. Associations of DED classification and corneal staining with potential risk factors were estimated using multivariate logistic regression. For statistical analysis $\mathrm{P}<0.05$ or less was accepted as significant.

\section{Results}

\section{Characteristics of subjects}

The purpose of this survey is to explore the characteristics of DED patients among the working-class population in Shanghai, a typical metropolis. According to the data, the age of 21-40 was the peak year range of functional DED, accounting for $70.4 \%$ of the total enrolled subjects. There were more female patients than male patients (1.27:1), and subjects with college degree and above accounted for $87.86 \%$. The subjects' occupations included various industries in the metropolis. Among them, IT practitioners, finance, teachers, scientific researchers, computer designers, market and consultants were most prominent, accounting for $78.76 \%$ of the total functional DED subjects. In 527 DED subjects, 116 subjects were ADDE, 239 subjects were EDE, and 172 subjects were mixed type (Table 1). 
Table 1

Subjects' characteristics

\begin{tabular}{|c|c|c|c|c|c|}
\hline Age & N & 527 & Contact lens types & $\mathbf{N}$ & 118 \\
\hline$\leq 20$ & $\begin{array}{l}\mathrm{n} \\
(\%)\end{array}$ & $4(0.76)$ & Daily & $\begin{array}{l}\mathrm{n} \\
(\%)\end{array}$ & $65(55.09)$ \\
\hline $21-30$ & $\begin{array}{l}n \\
(\%)\end{array}$ & 178(33.78) & Monthly & $\begin{array}{l}\mathrm{n} \\
(\%)\end{array}$ & $32(27.12)$ \\
\hline $31-40$ & $\begin{array}{l}\mathrm{n} \\
(\%)\end{array}$ & 193(36.62) & Quarterly & $\begin{array}{l}\mathrm{n} \\
(\%)\end{array}$ & $10(8.47)$ \\
\hline $41-50$ & $\begin{array}{l}n \\
(\%)\end{array}$ & $113(21.44)$ & Half year & $\begin{array}{l}\mathrm{n} \\
(\%)\end{array}$ & $8(6.78)$ \\
\hline$\geq 51$ & $\begin{array}{l}\mathrm{n} \\
(\%)\end{array}$ & $39(7.4)$ & Yearly & $\begin{array}{l}\mathrm{n} \\
(\%)\end{array}$ & $3(2.54)$ \\
\hline Education & $\mathbf{N}$ & 527 & Work overtime & $\mathbf{N}$ & 527 \\
\hline Junior high school or below & $\begin{array}{l}\mathrm{n} \\
(\%)\end{array}$ & $3(0.57)$ & Yes & $\begin{array}{l}\mathrm{n} \\
(\%)\end{array}$ & $249(47.25)$ \\
\hline $\begin{array}{l}\text { High school or secondary } \\
\text { school }\end{array}$ & $\begin{array}{l}\mathrm{n} \\
(\%)\end{array}$ & $61(11.57)$ & No & $\begin{array}{l}\mathrm{n} \\
(\%)\end{array}$ & $278(52.75)$ \\
\hline University or college & $\begin{array}{l}\mathrm{n} \\
(\%)\end{array}$ & 281(53.32) & Overtime(hour) & $\mathbf{N}$ & 249 \\
\hline Graduate & $\begin{array}{l}\mathrm{n} \\
(\%)\end{array}$ & 182(34.54) & $<1$ & $\begin{array}{l}\mathrm{n} \\
(\%)\end{array}$ & $52(20.88)$ \\
\hline Gender & N & & $1-2$ & $\begin{array}{l}\mathrm{n} \\
(\%)\end{array}$ & $123(49.40)$ \\
\hline Male & $\begin{array}{l}\mathrm{n} \\
(\%)\end{array}$ & 232(44.02) & $2-3$ & $\begin{array}{l}\mathrm{n} \\
(\%)\end{array}$ & $46(18.47)$ \\
\hline Female & $\begin{array}{l}n \\
(\%)\end{array}$ & 295(55.98) & $>3$ & $\begin{array}{l}\mathrm{n} \\
(\%)\end{array}$ & $28(11.25)$ \\
\hline Profession & $\mathbf{N}$ & 527 & Get up & $\mathbf{N}$ & 527 \\
\hline IT pratitioner & $\begin{array}{l}\mathrm{n} \\
(\%)\end{array}$ & $92(17.46)$ & Before 6 & $\begin{array}{l}\mathrm{n} \\
(\%)\end{array}$ & $56(10.62)$ \\
\hline Office staff & $\begin{array}{l}\mathrm{n} \\
(\%)\end{array}$ & $42(7.97)$ & $6-7$ & $\begin{array}{l}\mathrm{n} \\
(\%)\end{array}$ & $149(28.27)$ \\
\hline Financial staff & $\begin{array}{l}\mathrm{n} \\
(\%)\end{array}$ & $46(8.73)$ & $7-8$ & $\begin{array}{l}\mathrm{n} \\
(\%)\end{array}$ & $251(47.63)$ \\
\hline Teacher/researcher & $\begin{array}{l}\mathrm{n} \\
(\%)\end{array}$ & 103(19.54) & After 8 & $\begin{array}{l}\mathrm{n} \\
(\%)\end{array}$ & 71(13.47) \\
\hline Computer design & $\begin{array}{l}\mathrm{n} \\
(\%)\end{array}$ & $79(15.00)$ & Sleeping & $\mathbf{N}$ & 527 \\
\hline
\end{tabular}

Subjects' characteristics were recorded. According to our clinical experience, we formulated a questionnaire to investigate the possible problems of functional DED in the daily work and life of working-classes, and made corresponding records and preliminary data analysis on these problems. 


\begin{tabular}{|c|c|c|c|c|c|}
\hline Age & $\mathbf{N}$ & 527 & Contact lens types & $\mathbf{N}$ & 118 \\
\hline Consultant & $\begin{array}{l}\mathrm{n} \\
(\%)\end{array}$ & $53(10.06)$ & Before 9 & $\begin{array}{l}\mathrm{n} \\
(\%)\end{array}$ & 18(3.42) \\
\hline Others & $\begin{array}{l}\mathrm{n} \\
(\%)\end{array}$ & $112(21.24)$ & $9-11$ & $\begin{array}{l}n \\
(\%)\end{array}$ & $117(22.20)$ \\
\hline DED classification & $\mathbf{N}$ & 527 & $11-12$ & $\begin{array}{l}\mathrm{n} \\
(\%)\end{array}$ & 299(56.74) \\
\hline ADDE & $n(\%)$ & $\begin{array}{l}116 \\
(22.01)\end{array}$ & After 12 & $\begin{array}{l}\mathrm{n} \\
(\%)\end{array}$ & $93(17.64)$ \\
\hline EDE & $n(\%)$ & $\begin{array}{l}239 \\
(45.35)\end{array}$ & Deep sleep(hour) & $\mathbf{N}$ & 527 \\
\hline Mixed DED & $n(\%)$ & $\begin{array}{l}172 \\
(32.64)\end{array}$ & $<5$ & $\begin{array}{l}n \\
(\%)\end{array}$ & $89(16.88)$ \\
\hline Visual Terminal & $\mathbf{N}$ & 527 & $5-6$ & $\begin{array}{l}\mathrm{n} \\
(\%)\end{array}$ & 118(22.39) \\
\hline Mobile & $\begin{array}{l}\mathrm{n} \\
(\%)\end{array}$ & $396(75.14)$ & $6-7$ & $\begin{array}{l}\mathrm{n} \\
(\%)\end{array}$ & $217(41.18)$ \\
\hline computer & $\begin{array}{l}\mathrm{n} \\
(\%)\end{array}$ & $426(80.83)$ & $7-8$ & $\begin{array}{l}\mathrm{n} \\
(\%)\end{array}$ & $93(17.65)$ \\
\hline TV & $\begin{array}{l}\mathrm{n} \\
(\%)\end{array}$ & 104(19.73) & $>8$ & $\begin{array}{l}\mathrm{n} \\
(\%)\end{array}$ & $10(1.90)$ \\
\hline E-book & $\begin{array}{l}\mathrm{n} \\
(\%)\end{array}$ & $26(4.93)$ & $\begin{array}{l}\text { Sleeping Days after } \\
\text { 12:00/week }\end{array}$ & $\mathbf{N}$ & 527 \\
\hline 3 or more & $\begin{array}{l}\mathrm{n} \\
(\%)\end{array}$ & $137(26.00)$ & $<1$ & $\begin{array}{l}\mathrm{n} \\
(\%)\end{array}$ & $82(15.55)$ \\
\hline Computer time(hour/day) & $\mathbf{N}$ & 426 & $1-2$ & $\begin{array}{l}\mathrm{n} \\
(\%)\end{array}$ & $215(40.80)$ \\
\hline$<4$ & $\begin{array}{l}n \\
(\%)\end{array}$ & $29(6.81)$ & $3-5$ & $\begin{array}{l}\mathrm{n} \\
(\%)\end{array}$ & $158(30.00)$ \\
\hline $4-6$ & $\begin{array}{l}\mathrm{n} \\
(\%)\end{array}$ & 73(17.13) & $\geq 6$ & $\begin{array}{l}\mathrm{n} \\
(\%)\end{array}$ & $72(13.65)$ \\
\hline $6-8$ & $\begin{array}{l}\mathrm{n} \\
(\%)\end{array}$ & $228(53.52)$ & Excessive working pressure & $\mathbf{N}$ & 527 \\
\hline$>8$ & $\begin{array}{l}n \\
(\%)\end{array}$ & $96(22.54)$ & Yes & $\begin{array}{l}\mathrm{n} \\
(\%)\end{array}$ & $293(55.60)$ \\
\hline Mobile time(hour/day) & $\mathbf{N}$ & 396 & No & $\begin{array}{l}\mathrm{n} \\
(\%)\end{array}$ & $234(44.40)$ \\
\hline$<4$ & $\begin{array}{l}\mathrm{n} \\
(\%)\end{array}$ & $163(41.17)$ & Anxiety & $\mathbf{N}$ & 527 \\
\hline
\end{tabular}

Subjects' characteristics were recorded. According to our clinical experience, we formulated a questionnaire to investigate the possible problems of functional DED in the daily work and life of working-classes, and made corresponding records and preliminary data analysis on these problems. 


\begin{tabular}{|c|c|c|c|c|c|}
\hline Age & $\mathbf{N}$ & 527 & Contact lens types & $\mathbf{N}$ & 118 \\
\hline $4-6$ & $\begin{array}{l}\mathrm{n} \\
(\%)\end{array}$ & $149(37.58)$ & Yes & $\begin{array}{l}\mathrm{n} \\
(\%)\end{array}$ & 205(38.90) \\
\hline $6-8$ & $\begin{array}{l}\mathrm{n} \\
(\%)\end{array}$ & $60(15.18)$ & No & $\begin{array}{l}\mathrm{n} \\
(\%)\end{array}$ & $322(61.10)$ \\
\hline$>8$ & $\begin{array}{l}\mathrm{n} \\
(\%)\end{array}$ & $24(6.07)$ & Exercise & $\mathbf{N}$ & 527 \\
\hline TV time(hour/day) & N & 104 & Yes & $\begin{array}{l}\mathrm{n} \\
(\%)\end{array}$ & $224(42.50)$ \\
\hline$<1$ & $\begin{array}{l}\mathrm{n} \\
(\%)\end{array}$ & $8(7.69)$ & No & $\begin{array}{l}\mathrm{n} \\
(\%)\end{array}$ & $303(57.50)$ \\
\hline $1-3$ & $\begin{array}{l}\mathrm{n} \\
(\%)\end{array}$ & $39(37.50)$ & Exercise frequency/week & $\mathbf{N}$ & 224 \\
\hline $3-6$ & $\begin{array}{l}\mathrm{n} \\
(\%)\end{array}$ & $44(42.31)$ & $1-2$ & $\begin{array}{l}\mathrm{n} \\
(\%)\end{array}$ & $141(62.95)$ \\
\hline$>6$ & $\begin{array}{l}\mathrm{n} \\
(\%)\end{array}$ & $13(12.50)$ & $3-4$ & $\begin{array}{l}\mathrm{n} \\
(\%)\end{array}$ & $56(25.00)$ \\
\hline Work under air-conditioner & N & 406 & $>5$ & $\begin{array}{l}\mathrm{n} \\
(\%)\end{array}$ & $27(12.05)$ \\
\hline$<3$ & $\begin{array}{l}\mathrm{n} \\
(\%)\end{array}$ & $63(15.52)$ & Exercise time(hour) & $\mathbf{N}$ & 224 \\
\hline $3-5$ & $\begin{array}{l}n \\
(\%)\end{array}$ & $149(36.70)$ & $<0.5$ & $\begin{array}{l}\mathrm{n} \\
(\%)\end{array}$ & $55(24.55)$ \\
\hline $5-8$ & $\begin{array}{l}\mathrm{n} \\
(\%)\end{array}$ & $160(39.41)$ & $0.5-1$ & $\begin{array}{l}\mathrm{n} \\
(\%)\end{array}$ & $102(45.54)$ \\
\hline$>8$ & $\begin{array}{l}\mathrm{n} \\
(\%)\end{array}$ & $34(8.37)$ & $1-2$ & $\begin{array}{l}\mathrm{n} \\
(\%)\end{array}$ & $47(20.98)$ \\
\hline Decoration & N & 527 & $2-3$ & $\begin{array}{l}\mathrm{n} \\
(\%)\end{array}$ & $17(7.59)$ \\
\hline Yes & $\begin{array}{l}n \\
(\%)\end{array}$ & 69(13.09) & $>3$ & $\begin{array}{l}\mathrm{n} \\
(\%)\end{array}$ & $3(1.34)$ \\
\hline No & $\begin{array}{l}\mathrm{n} \\
(\%)\end{array}$ & $458(86.01)$ & Smoking & $\mathbf{N}$ & 527 \\
\hline $\begin{array}{l}\text { Irritation caused by } \\
\text { decoration }\end{array}$ & $\mathbf{N}$ & 69 & Yes & $\begin{array}{l}\mathrm{n} \\
(\%)\end{array}$ & 19(3.61) \\
\hline Yes & $\begin{array}{l}\mathrm{n} \\
(\%)\end{array}$ & $47(68.12)$ & No & $\begin{array}{l}\mathrm{n} \\
(\%)\end{array}$ & $508(96.39)$ \\
\hline No & $\begin{array}{l}\mathrm{n} \\
(\%)\end{array}$ & $22(31.88)$ & Amount (cigarette) & $\mathbf{N}$ & 19 \\
\hline
\end{tabular}

Subjects' characteristics were recorded. According to our clinical experience, we formulated a questionnaire to investigate the possible problems of functional DED in the daily work and life of working-classes, and made corresponding records and preliminary data analysis on these problems. 


\begin{tabular}{|c|c|c|c|c|c|}
\hline Age & $\mathbf{N}$ & 527 & Contact lens types & $\mathbf{N}$ & 118 \\
\hline Contact lens & $\mathbf{N}$ & 527 & $<5$ & $\begin{array}{l}\mathrm{n} \\
(\%)\end{array}$ & $1(5.26)$ \\
\hline Yes & $\begin{array}{l}\mathrm{n}_{(\%)} \\
\text { (\%) }\end{array}$ & 118(22.39) & $5-10$ & $\begin{array}{l}n \\
(\%)\end{array}$ & $3(15.79)$ \\
\hline No & $\begin{array}{l}\mathrm{n} \\
(\%)\end{array}$ & $409(77.61)$ & $10-20$ & $\begin{array}{l}\mathrm{n} \\
(\%)\end{array}$ & $10(52.63)$ \\
\hline Time/week & $\mathbf{N}$ & 118 & $>20$ & $\begin{array}{l}\mathrm{n} \\
(\%)\end{array}$ & $5(26.32)$ \\
\hline $1-2$ & $\begin{array}{l}n_{(\%)} \\
(\%)\end{array}$ & 43(36.44) & Alcohol & $\mathbf{N}$ & 527 \\
\hline $3-4$ & $\begin{array}{l}\mathrm{n} \\
(\%)\end{array}$ & $49(41.53)$ & Yes & $\begin{array}{l}\mathrm{n} \\
(\%)\end{array}$ & $112(21.25)$ \\
\hline$\geq 5$ & $\begin{array}{l}\mathrm{n}_{(\%)} \\
(\%)\end{array}$ & $26(22.03)$ & No & $\begin{array}{l}\mathrm{n} \\
(\%)\end{array}$ & $415(78.75)$ \\
\hline Take out when sleeping & $\mathbf{N}$ & 118 & Time/week & $\mathbf{N}$ & 112 \\
\hline Yes & $\begin{array}{l}\mathrm{n}_{(\%)} \\
\text { (\%) }\end{array}$ & 112(94.92) & $1-2$ & $\begin{array}{l}n \\
(\%)\end{array}$ & 75(66.96) \\
\hline No & $\begin{array}{l}n \\
(\%)\end{array}$ & $6(5.08)$ & $3-4$ & $\begin{array}{l}n \\
(\%)\end{array}$ & $23(20.54)$ \\
\hline Water content & $\mathbf{N}$ & 118 & $\geq 5$ & $\begin{array}{l}\mathrm{n} \\
(\%)\end{array}$ & $14(12.50)$ \\
\hline High & $\begin{array}{l}\mathrm{n}_{(\%)} \\
\text { (1) }\end{array}$ & $69(58.47)$ & & & \\
\hline Middle & $\begin{array}{l}\mathrm{n}_{(\%)} \\
\text { (\%) }\end{array}$ & $41(34.75)$ & & & \\
\hline Low & $\begin{array}{l}\mathrm{n}_{(\%)} \\
\text { (1) }\end{array}$ & $8(6.78)$ & & & \\
\hline $\begin{array}{l}\text { Subjects' characteristics } \\
\text { investigate the possible } \\
\text { corresponding records an }\end{array}$ & $\begin{array}{l}\text { orde } \\
\text { of }\end{array}$ & $\begin{array}{l}\text { according to } \\
\text { tional DED i } \\
\text { ata analysis }\end{array}$ & $\begin{array}{l}\text { inical experience, we } \\
\text { daily work and life o } \\
\text { ese problems. }\end{array}$ & $\begin{array}{l}\text { a que } \\
\text { asses }\end{array}$ & $\begin{array}{l}\text { ionnaire to } \\
\text { nd made }\end{array}$ \\
\hline
\end{tabular}

\section{Functional DED classification}

From the clinical examination results of 527 DED patients, we found that most subjects were EDE (45.35\%), and many DED subjects actually coexisted symptoms and signs of two types of DED (32.64\%), which is similar with the conclusion of TFOS DEWS II Definition and Classification Report [1]. Specially, the dominant proportion of $A D D E$ or EDE was variable due to their underlying reasons. According to multivariate logistic regression analysis, DED classification has no correlation with age, gender, education, stress and anxiety, while there were other risk factors. Namely, the frequent use of electronic screen, air conditioner, contact lens, smoking and drinking were associated with EDE. Notably, deep sleep seemed to be a protective factor (Table 1, Table 2). 
Table 2

Multivariate logistic regression analysis of classification and predictors

\begin{tabular}{|c|c|c|c|c|c|c|}
\hline \multirow[t]{2}{*}{ Predictors } & \multirow[t]{2}{*}{ S.E. } & \multirow[t]{2}{*}{ Wald } & \multirow[t]{2}{*}{$p$} & \multirow[t]{2}{*}{ Odds ratio } & \multicolumn{2}{|c|}{ Odds ratio $95 \% \mathrm{Cl}$} \\
\hline & & & & & Lower & Upper \\
\hline Gender & 0.300 & 0.467 & 0.494 & 0.815 & 0.453 & 1.466 \\
\hline Age & 0.222 & 3.500 & 0.061 & 1.516 & 0.980 & 2.345 \\
\hline Education & 0.299 & 0.016 & 0.901 & 1.038 & 0.578 & 1.863 \\
\hline Computer & 0.389 & 7.232 & 0.007 * & 2.847 & 1.328 & 6.104 \\
\hline Mobile & 0.295 & 8.373 & 0.004 * & 2.349 & 1.317 & 4.188 \\
\hline TV & 0.260 & 1.650 & 0.199 & 0.716 & 0.431 & 1.192 \\
\hline Deep sleep & 0.154 & 6.035 & $0.014 \#$ & 0.685 & 0.507 & 0.926 \\
\hline Stay up later & 0.214 & 7.271 & $0.007 *$ & 1.781 & 1.171 & 2.710 \\
\hline air-conditioner & 0.856 & 0.039 & 0.843 & 1.184 & 0.221 & 6.347 \\
\hline Decoration & 0.421 & 6.046 & $0.014 *$ & 2.817 & 1.234 & 6.430 \\
\hline Pressure & 0.273 & 2.050 & 0.152 & 0.676 & 0.396 & 1.155 \\
\hline Anxiety & 0.154 & 0.026 & 0.871 & 0.975 & 0.721 & 1.319 \\
\hline Contact lens & 0.253 & 8.660 & $0.003^{*}$ & 2.104 & 1.282 & 3.453 \\
\hline Overtime work & 0.417 & 1.530 & 0.216 & 0.597 & 0.263 & 1.352 \\
\hline Smoking & 0.336 & 20.750 & $0.000 *$ & 4.630 & 2.394 & 8.953 \\
\hline Drinking & 0.219 & 6.995 & $0.008^{*}$ & 1.786 & 1.162 & 2.746 \\
\hline
\end{tabular}

\section{Use of electronic screen}

The electronic screens used by the enrolled DED patients in their daily work and life were primarily mobile phones and computers, $(75.14 \%$ and $80.83 \%$, respectively). This shows that computers and mobile phones not only were the main electronic visual tools, but also used simultaneously on most occasions. Additionally, multivariate regression data showed that computer was a risk factor for both DED classification $(p=0.007,95 \%$ Cl: $1.328-$ $6.104)$ and ocular surface damage ( $p=0.007,95 \% \mathrm{Cl}: 1.142-2.315)$. Similarly, Mobile phone also had a damaging effect on DED classification ( $p=0.004,95 \% \mathrm{Cl}$ : $1.317-4.188)$ and ocular surface $(p=0.003,95 \% \mathrm{Cl}$ : 1.289-3.330). Other devices with electronic screens, such as TV and e-book, were relatively less frequently used in their work and life (19.73\% and $4.93 \%$ respectively). Besides, some DED patients often used three or more video devices (26.00\%) in their daily work and life (Table 1-Table 3). 


\section{Working environment and decoration}

An important factor of work environment affecting dry eye was the exposure to air conditioning. A majority (77.04\%) of the interviewed DED patients affirmed that they worked and lived under air conditioning. Most of them were in the office, the time range was mostly 3-8 hours/day (76.11\%). Notably, many subjects also confirmed that they also used air conditioning continuously at home when the temperature is too cold or too hot. Even worse, the subjects admitted that the air-conditioner usually kept on during the sleep time without any humidification measures in the bedroom. Our multivariate regression data showed that work under air conditioned environment was a risk factor for ocular surface lesion ( $p=0.006,95 \% \mathrm{Cl}: 1.240-3.493)$, while it had no effect on DED classification ( $p=0.843,95 \% \mathrm{Cl}$ : $0.221-6.347)$. In addition, the newly decorated room or workplace was also one of the main risk factor for DED classification $(p=0.014,95 \% \mathrm{Cl}: 1.234-6.430)$ and ocular surface lesion $(p=0.038$, $95 \% \mathrm{Cl}: 1.039-3.810)$. Although the proportion of those patients was not dominant (13.09\%), the irritated symptoms were obvious, mainly manifested as eye dryness, photophobia and eye irritation, even conjunctival congestion, mild edema and positive corneal staining (Table 1-Table 3, Fig. 1, Fig. 2).

\section{Contact lens}

Both the results of questionnaire and the clinical examination indicated that contact lens was a leading risk factor for EDE (Table 2, $p=0.003,95 \% \mathrm{Cl}: 1.282-3.453$ ) and ocular surface complications (Table 3, $p=0.025,95 \% \mathrm{Cl}$ : 1.087-3.399). In the survey, we found that the proportion of DED patients who used contact lenses was not very high (22.39\%), while the incidence of symptoms and signs were much higher than other DED patients. The frequency of use in most patients was less than 4 times a week $(77.97 \%)$. The most prevalent contact lens was the high water content (58.47\%) and daily disposable type (55.09\%). Most patients took out the contact lenses before sleeping (94.92\%). The incidence of classification EDE was prevalent, and dry eye symptoms such as eye dryness, gritty sensation, photophobia and ocular surface irritation were uniformly much higher than that of other factors. Actually, the incidence of EDE and ocular surface damage such as corneal epithelial exfoliation were invariably much more likely to be detected than that of other factors in our clinical examinations (Table 1, Fig. 3, P $<0.001$ ). 
Table 3

Multivariate logistic regression analysis of corneal staining and predictors

\begin{tabular}{|c|c|c|c|c|c|c|}
\hline \multirow[t]{2}{*}{ Predictors } & \multirow[t]{2}{*}{ S.E. } & \multirow[t]{2}{*}{ Wald } & \multirow[t]{2}{*}{$p$} & \multirow[t]{2}{*}{ Odds ratio } & \multicolumn{2}{|c|}{ Odds ratio $95 \% \mathrm{Cl}$} \\
\hline & & & & & Lower & Upper \\
\hline Gender & 0.312 & 3.681 & 0.055 & 1.818 & 0.987 & 3.347 \\
\hline Age & 0.241 & 0.385 & 0.535 & 0.861 & 0.537 & 1.381 \\
\hline Education & 0.436 & 11.728 & 0.001 & 0.224 & 0.095 & 0.528 \\
\hline Computer & 0.180 & 7.280 & $0.007^{\star}$ & 1.626 & 1.142 & 2.315 \\
\hline Mobile & 0.242 & 9.042 & $0.003^{*}$ & 2.072 & 1.289 & 3.330 \\
\hline TV & 0.255 & 0.085 & 0.770 & 1.077 & 0.654 & 1.776 \\
\hline Deep sleep & 0.282 & 7.706 & $0.006 \#$ & 0.458 & 0.263 & 0.795 \\
\hline Stay up later & 0.196 & 13.272 & $0.000 *$ & 2.044 & 1.391 & 3.002 \\
\hline Air conditioner & 0.264 & 7.686 & $0.006^{*}$ & 2.081 & 1.240 & 3.493 \\
\hline Decoration & 0.332 & 4.303 & $0.038^{*}$ & 1.989 & 1.039 & 3.810 \\
\hline Pressure & 0.318 & 2.527 & 0.112 & 0.604 & 0.324 & 1.125 \\
\hline Anxiety & 0.400 & 1.990 & 0.158 & 1.757 & 0.803 & 3.844 \\
\hline Contact lens & 0.291 & 5.051 & $0.025^{\star}$ & 1.922 & 1.087 & 3.399 \\
\hline Overtime work & 0.219 & 1.430 & 0.232 & 1.300 & 0.846 & 1.998 \\
\hline Smoking & 0.187 & 0.585 & 0.445 & 1.154 & 0.799 & 1.666 \\
\hline Drinking & 0.402 & 0.454 & 0.500 & 1.311 & 0.596 & 2.884 \\
\hline
\end{tabular}

\section{Deep sleep}

Multivariate regression analysis of the data show that deep sleep appears to be a protective factor of functional dry eye disease in DED classifications $(p=0.014,95 \% \mathrm{Cl}$ : $0.507-0.926)$ and ocular surface lesion $(p=0.006,95 \% \mathrm{Cl}$ : $0.263-0.795)$. In the classification analysis of DED, we found that, with the increase of deep sleep time, the incidence of ADDE increased significantly, accordingly, the incidence of EDE gradually decreased (Table 2, 3, Fig. 4, $\mathrm{P}<0.001)$. Furthermore, deep sleep also seemed to be a protective factor for maintaining the function of ocular surface tissue. With the increase of deep sleep time, the incidence of corneal positive staining also showed a gradual downward trend. The incidence of positive corneal staining in less than 6 hours deep sleep subjects were significantly higher than that in more than 7 hours deep sleep subjects (Fig. 4, P<0.001).

\section{Discussion}


As Shanghai is an international metropolis, the working class population in this city is experiencing a faster and faster pace of work and life. According to our clinical data, the functional DED, which is closely related to work and life, is becoming a prominent problem in working class. In clinical work, we examine and treat a large number of dry eye patients every day, who are vigorous and healthy working-class, without definite primary diseases, but seem fatigue or in a sub-health state. They come from all walks of life, and exhibit similar characteristics: fast working pace, high work or life stress, frequent overtime, irregular life style, inseparable with electronic screens in work or life, frequent use of contact lenses, etc.

Nowadays, functional DED caused by occupation, life and other related factors has been increasingly reported and recognized. Indoor environment, work environment, and general health were perceived as the main reasons for developing dry eye. Occupations such as office workers and in indoor occupations with high screen use were in higher risk than in outdoor and active occupation. Importantly, they suggested that lifestyle intervention may be a promising management option for dry eye disease [7-9]. According to the results of our questionnaire, among the wage earners in Shanghai, the incidence of functional DED is high, involving a wide range of occupations. The enrolled functional DED patients who complained of dry eye or diagnosed functional DED were very common, involving a variety of industries and occupations. We believe that this is mainly related to the working environment, rhythm and mode of modern cities. Although each type of work has its inherent particularity, there also share many similar characteristics among the types of work, such as high working pressure, fast pace, longterm high-frequency use of computers and mobile phones, long-term work in air-conditioning environment, etc., which will inevitably affect the physical and mental health. It should be noted that, although these dry eye patients come from different industries, the pathogenic factors of DED were similar, which indicate that there might be little correlation with the differences in their occupations or nature of work.

It is known that DED comprises two types: aqueous deficient dry eye (ADDE) and evaporative dry eye (EDE). According to the TFOS DEWS II definition and classification Report, Aqueous deficiency describes conditions affecting the lacrimal gland, while evaporative dry eye is understood to occur with conditions affecting the eyelid or the ocular surface. EDE is devoted a larger area on the diagram than ADDE in recognition of the current understanding that an evaporative component to DED is more common than an aqueous deficient component. Whereas, it is possible that ADDE can occur without obvious signs of EDE and vice versa, as DED progresses, it is increasingly likely that characteristics of both ADDE and EDE will become evident $[1,10]$. In our survey, we found that most of the selected dry eye patients are EDE patients. While, it should be say that, some of them actually suffered from two types DED at the same time, just as the main clinical manifestations are ADDE or EDE. This is consistent with TFOS DEWS II reports.

Similar to previous reports, long-term high-frequency use of video equipment is a known risk factor. In addition to the stimulation of light to the eyes, it mainly leads to the reduction of blink times due to the concentration of attention. As the duration of covering the ocular surface by tear film is shorter than the time gap of two blinks, there is actually part time that no tear film covered in the ocular tissues between the interval of two blinks, indirectly leading to a exposure of ocular surface, the similar effect of ADDE, which results in an increase of tear osmotic pressure, inflammatory factors release or even triggering inflammation in ocular surface.

As for working environment, functional DED is mainly related to air conditioning environment and room decoration. The air conditioning working environment mainly affects the evaporation of tear film. In the newly decorated environment, as the pungent smell, paint and other decoration materials stimulates the eyes and nose, 
the reflex secretion of tear, the irritation of lacrimal gland unit (LFU), and the damage of ocular surface tissue are consequently caused.

Here, l'd like to emphasize that, we should pay more attention to the damage of contact lens to ocular surface tissue and functional DED. According to previous studies, the damage of contact lens on ocular surface and tear film can be summarized as: Firstly, the direct frictional effect on corneal and conjunctival tissues and cells. This kind of continuous friction leads to the damage of conjunctiva and corneal epithelial, causes the edema, necrosis and abscess of conjunctival epithelium or stromal cells near cornea and limbus, damages the natural barrier of ocular surface epithelial cells secondary infiltration of inflammatory cells including dendritic cells, releases various inflammatory factors, and causes keratitis $[11,12]$. The second is the effect on eyelid and meibomian gland. The contact lens not only rubs the conjunctiva and cornea, but also rubs the upper and lower meibomian glands. This continuous friction can not only damage the conjunctiva, but also affect the normal formation and function of the meibomian gland duct cells and gland cells, interfere with the normal synthesis and secretion of the glands [13]. Finally, the effect on tear film kinetics and ocular surface tissues. The contact lens is placed on the ocular surface, mechanically isolate the anchoring effect of tear film and corneal epithelial cells, affects the normal distribution and turnover of tear film, as well as its damage to the ocular surface tissue and cells, triggers lipid oxidation and the release of inflammatory factors, etc., and resulting in the abnormality of tear film formation and function [13, 14].

In our questionnaire, we did find that the functional DED subjects who used contact lens, regardless of the type, exhibited apparent dry eye symptoms and ocular surface damage than that induced by other factors. In addition to the obvious complaints of dry eyes and foreign body sensation, we also found the ducts of meibomian glands were often congestive, swollen and stagnant. The conjunctiva was also in a state of chronic hyperemia. Occasionally, a fraction of mucilaginous secretion can be found in the conjunctival sac. In addition, the corneal epithelium was usually in a state of edema and, the positive fluorescein staining was invariably detected than that of functional DED caused by other reasons. Moreover, the ocular surface inflammation or even keratitis was usually traced. Additionally, in functional DED subjects who used contact lenses or sleep disorder, we usually find that the positive fluorescein staining was located in the lower part of cornea. We speculate that it might be attributed to the following reasons: the first is the bell's phenomenon, a reflex reaction characterized by an upward and usually slightly outward rolling of the eyes associated with actual or attempted bilateral eyelid closure, which leads to incomplete closure of eyelid and long-term exposure of the lower part cornea [15]. Second, the inflammatory factors in the tear film are gathered in the lower tear meniscus due to the gravity, which makes the concentration of inflammatory factors in the lower tear river markedly increased, the lower part of the cornea continuously immersed in the high-concentrated inflammatory tear film, leading to epithelial damage or even keratitis in the lower cornea.

Notably, our statistical results also show that deep sleep may be an important protective factor for DED. In modern society, due to fast work rhythm and high-strength life stress, poor sleep quality or even insomnia is becoming a thorny issue that troubles the working-class. In recent years, there are accumulating studies revealed that sleep deprivation (SD) has an important relationship with DED, SD decreased aqueous tear secretion, increased corneal epithelial cell defects, corneal sensitivity, and apoptosis; and induced squamous metaplasia of the corneal epithelium [16-18]. Normally, there is a self-maintenance process for ocular surface epithelium, the most important component element is microvilli, which is largely composed of glycoprotein that covers the surface of epithelial and other cells. Microvilli are essential for maintaining the lubrication and moisturization of epithelial 
cells on the ocular surface [19]. Animal experiments indicated that both PPARa and PPARY are involved in the formation of tear film and lipid secretion and the maintenance of ocular surface function. While sleep deprivation can induces DED through abnormal microvilli morphology of corneal superficial epithelial cells, which is caused by the continuous down-regulation of PPARa, transient receptor potentialvanilloid 6 (TRPV6) expression and Ezrin phosphorylation status $[20,21]$. Our questionnaire data and clinical examination results clearly show that the incidence of EDE is significantly higher in patients with less deep sleep time than ADDE, and the incidence of positive corneal staining is also kept high, while this trend has been changed with the increase of deep sleep time. This may imply that deep sleep is not only protective for reversing and rebuilding the formation and function of tear film, but also reducing functional DED and maintaining a normal ocular surface function.

It should be noted that, according to a large number of patients' data collected in our hospital, although the inducing factors of functional DED were various, most of them were retrospective, and the damage to ocular surface tissue was also reversible. Actually we found most of symptoms and signs of functional DED patients were greatly improved or even disappeared after they strictly followed our advices and tried to improve or eliminate some risk factors derived from their work or life. In view of this, we believe that for the functional DED patients, finding and eliminating the inducing factors in their ordinary work and life are more reliable and effective than simply passive physical or drug therapy. It is easy to understand that, the former is aimed to eliminate the pathogenic factors from the source, which is essentially a type of etiological treatment. While the latter is only alleviated the symptoms or signs of DED. It is merely a palliative treatment. Hence, we suggest that, for functional DED patients, it is more meaningful and preferable to inquire their medical history in detail, explain the illness, help and persuade them to clarify the pathogenic factors, exhort and urge them to quit the pernicious work and life habits, rather than simply passive drug therapy.

In conclusion, we believe that the functional DED in Shanghai is resulted from many factors. In addition to the dominant factors such as contact lenses, sleep disorder, use of electronic screens, air conditioning and decoration, DED is also related to some other less obvious factors such as work stress, living habits, social environment, etc. In Shanghai, the working-class is generally in a state of fast rhythm and tense pressure, which makes them resort to all conceivable means to work and live as efficiently as possible. In order to relax themselves, they turn to all means available including smoking and alcohol, video games, etc. From a deeper perspective, the results of our dry eye survey also reflect the epitome of the work and life of the working class in metropolis. It worths to mention that the functional DED has no primary causes, if we fully recognize and avoid these unhealthy habits and lifestyle, the functional DED may be completely cured and prevented. In light of this, we suggest that a healthy and regular work and life habit is the fundamental measure to treat and prevent functional DED, this should be fully realized and valued by our society. Finally, as this questionnaire is based on our long-term clinical observation, its results may provide some reasonable suggestions and actively avoid some unhealthy habits for the vast majority of functional DED patients.

\section{Abbreviations}

DED: dry eye disease; ADDE: aqueous deficient dry eye; EDE: evaporative dry eye; SS: Sjogren syndrome; LFU: lacrimal gland unit; SD: sleep deprivation; TRPV6: transient receptor potentialvanilloid 6

\section{Declarations}


The study was approved by the Institutional Review Board (IRB) of Huashan Hospital affiliated Fudan university, all participants gave informed consent. The study adhered to the tenets of the Declaration of Helsinki.

\section{Consent for publication}

Not applicable.

\section{Availability of data and materials}

The datasets generated analyzed during our current study are not publicly available due to patient's data privacy but can be made available from the corresponding author upon reasonable request.

\section{Competing Interests}

No.

\section{Funding}

This work was supported by the key project of Shanghai Science and Technology Commission on Biomedicine (nos. 18401970200) and Zhang Ren Inheritance Studio of National Famous and Aged Traditional Chinese Medicine Expert (nos. 1542962311683). Professor Nianhong Wang designed the questionnaire. Professor Zhang Ren made a dialectical study on the traditional Chinese medicine (TCM) theory of dry eye diseases.

\section{Authors' contributions}

Nianhong Wang designed the questionnaire, funding the questionnaire survey. Dan Chen, Yan Liu and Huan Weng collected the data. Huiying Wang appraised the data and clinical assessment. Weibao Xiao designed the questionnaire, observed the survey results, analyzed data and manuscript written.

\section{Acknowledgements}

None

\section{References}

1. Craig JP, Nichols KK, Akpek EK, Caffery B, Dua HS, Joo CK, Liu Z, Nelson JD, Nichols JJ. TFOS DEWS II Definition and Classification Report. Ocul Surf. 2017;15(3):276-283.

2. Pflugfelder, S.C. Management and therapy of dry eye disease: report of the Management and Therapy Subcommittee of the International Dry Eye WorkShop. Ocul Surf. 2007;5(2): 163-178.

3. Dana R, Bradley JL, Guerin A, Pivneva I, Stillman IÖ, Evans AM, Schaumberg DA. Estimated Prevalence and Incidence of Dry Eye Disease Based on Coding Analysis of a Large, All-age United States Health Care System. Am J Ophthalmol. 2019; 202:47-54.

4. Um SB, Yeom H, Kim NH, Kim HC, Lee HK, Suh I. Association between dry eye symptoms and suicidal ideation in a Korean adult population. PLoS One. 2018;13(6).

5. Lienert JP, Tarko L, Uchino M, Christen WG, Schaumberg DA. Long-term Natural History of Dry Eye Disease from the Patient's Perspective. Ophthalmology. 2016;123(2):425-433

6. Liang LY, Li J, Liu ZG. Focusing on the functional dry eye. Zhonghua Yan Ke Za Zhi. 2019;55(12):885-890 
7. Van Tilborg MM, Murphy PJ, Evans KS. Impact of dry eye symptoms and daily activities in a modern office. Optom Vis Sci. 2017;94(6):688-693

8. Kawashima M, Sano K, Takechi S, Tsubota K. Impact of lifestyle intervention on dry eye disease in office workers: a randomized controlled trial. J Occup Health. 2018;60(4):281-288

9. Bazeer S, Jansonius N, Snieder H, Hammond C, Vehof J. The relationship between occupation and dry eye. Ocul Surf. 2019;17(3):484-490.

10. Wolffsohn JS, Arita R, Chalmers R, Djalilian A, Dogru M, Dumbleton K,Gupta PK, Karpecki P, Lazreg S, Pult H, et al. TFOS DEWS II Diagnostic Methodology report. Ocul Surf. 15(3): 539-574.

11. McMonnies CW. Eye rubbing type and prevalence including contact lens 'removal-relief' rubbing. Clin Exp Optom. 2016; 99(4):366-372.

12. Dogan AS, Gurdal C, Arslan N. Corneal confocal microscopy and dry eye findings in contact lens discomfort patients. Cont Lens Anterior Eye. 2018;41(1):101-104.

13. Li W, Sun X, Wang Z, Zhang Y. A survey of contact lens-related complications in a tertiary hospital in China. Cont Lens Anterior Eye. 2018;(2):201-204.

14. Guillon M, Dumbleton KA, Theodoratos P, Wong S, Patel K, Banks G, Patel T. Association between contact lens discomfort and pre-lens tear film kinetics. Optom Vis Sci. 2016;93 (8):881-891.

15. Hall, A. J. Some observations on the acts of closing and opening the eyes. Br J Ophthalmol. 1936; 20(5):257295.

16. Yu X, Guo H, Liu X, Wang G, Min Y, Chen SS, Han SS, Chang RT, Zhao X, Hsing A, et al. Dry eye and sleep quality: a large community-based study in Hangzhou. Sleep. 2019;42 (11).

17. Ayaki M, Tsubota K, Kawashima M, Kishimoto T, Mimura M, Negishi K. Sleep Disorders are a Prevalent and Serious Comorbidity in Dry Eye. Invest Ophthalmol Vis Sci. 2018;59(14): DES143-DES150.

18. Li S, Ning K, Zhou J, Guo Y, Zhang H, Zhu Y, Zhang L, Jia C, Chen Y, Sol Reinach P, et al. Sleep deprivation disrupts the lacrimal system and induces dry eye disease. Exp Mol Med. 2018;50(3):e451.

19. Gipson IK, Argueso P. Role of mucins in the function of the corneal and conjunctival epithelia. Int Rev Cytol. 2013;231:1-49.

20. Jester JV, Potma E, Brown DJ. PPARy Regulates Mouse Meibocyte Differentiation and Lipid Synthesis. Ocul Surf. 2016;14(4):484-494.

21. Tang L, Wang X, Wu J, Li SM, Zhang Z, Wu S, Su T, Lin Z, Chen X, Liao X, et al. Sleep deprivation induces dry eye through inhibition of PPARa expression in corneal epithelium. Invest Ophthalmol Vis Sci. 2018;59(13): 5494-5508.

\section{Figures}




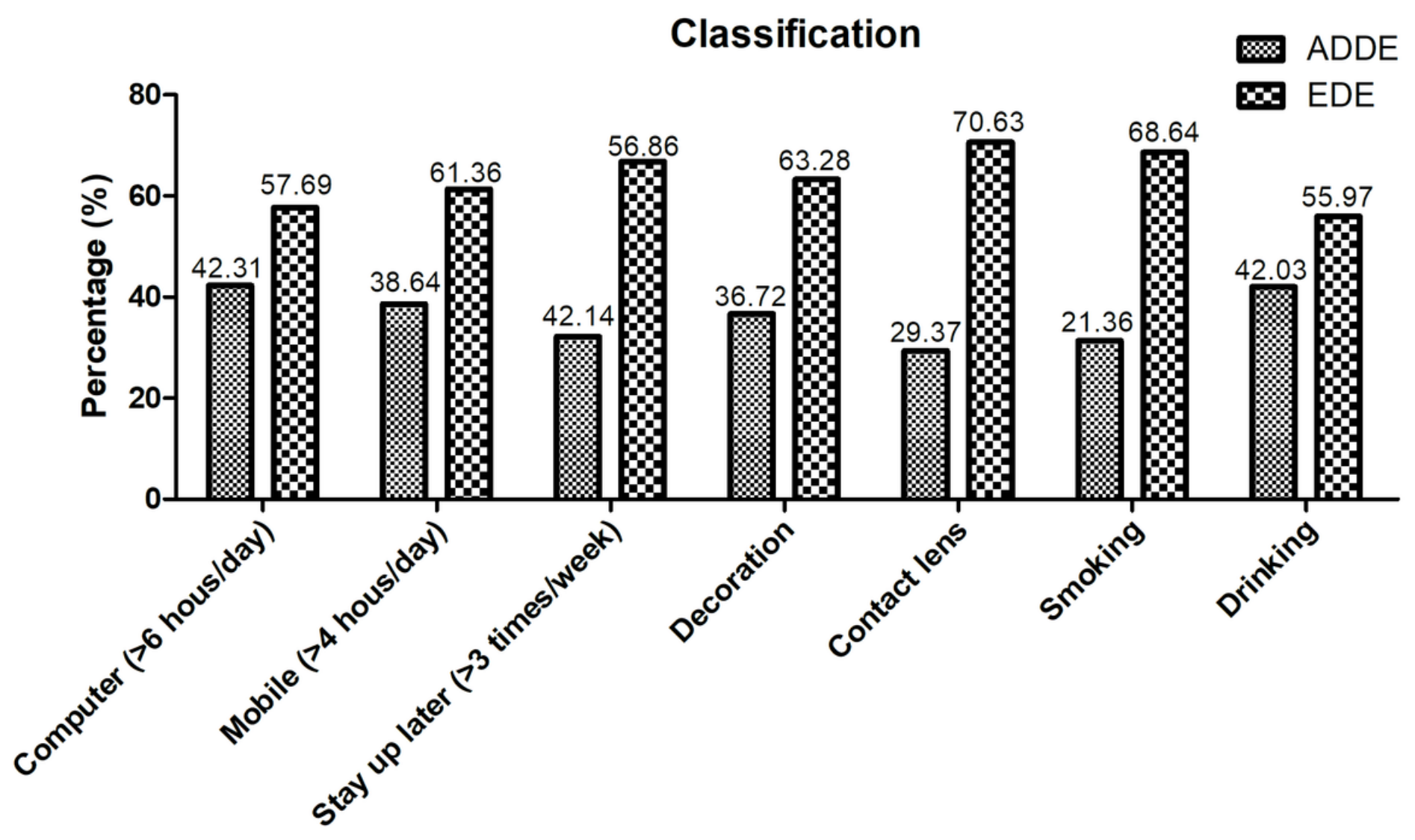

Figure 1

Percentage of ADDE and EDE in risk factors. According to the multivariate logistic regression analysis, we found that mobile phones, computers, staying up late, decoration, contact lenses, smoking and drinking were the risk factors of functional DED classification in working-class population. EDE is related to the habits from ordinary work and life such as high-frequency use of display terminals, long-term staying up late, contact lenses, smoking and alcohol, as well as the external factors such as air conditioning and decoration. Notably, among them, stay up later, smoking and contact lens exhibit the more obvious effects on functional DED classification. (Note: In this table, we include the mixed type in EDE and ADDE according to their dominant signs in order for comparison). 


\section{Positive staining}

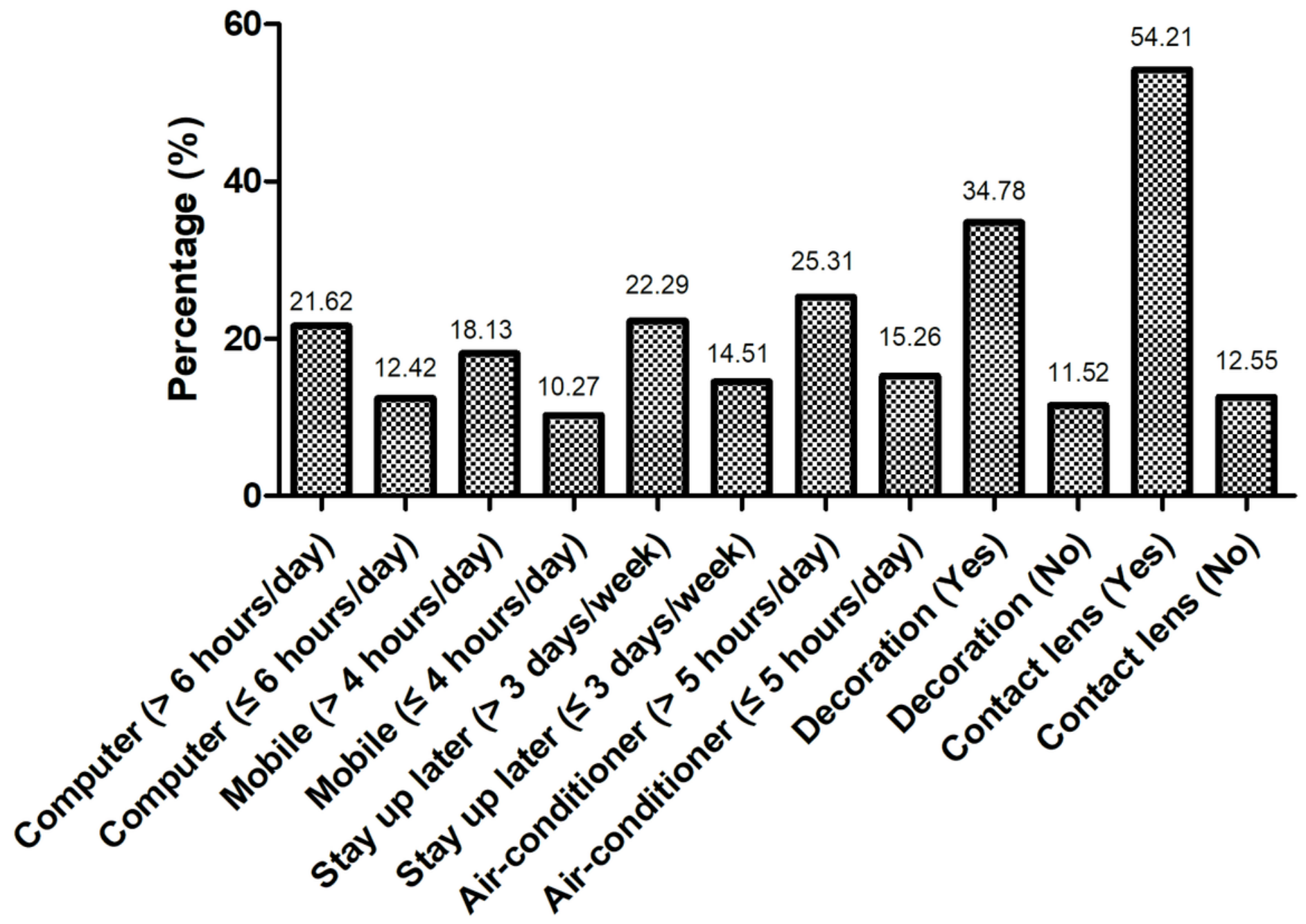

Figure 2

Percentage of positive corneal staining in risk factors. According to the multivariate logistic regression results of the data, mobile phones, computers, staying up late, air conditioning, decoration, contact lenses were the risk factors of corneal lesion. Similar to DED classification, by listed the percentage of each risk factor, we found that positive corneal staining is associated with high-frequency use of display terminals, long-term staying up late, contact lenses, as well as the external factors such as air conditioning and decoration. Among them, the decoration and contact lens have the most obvious effects on corneal lesion. 

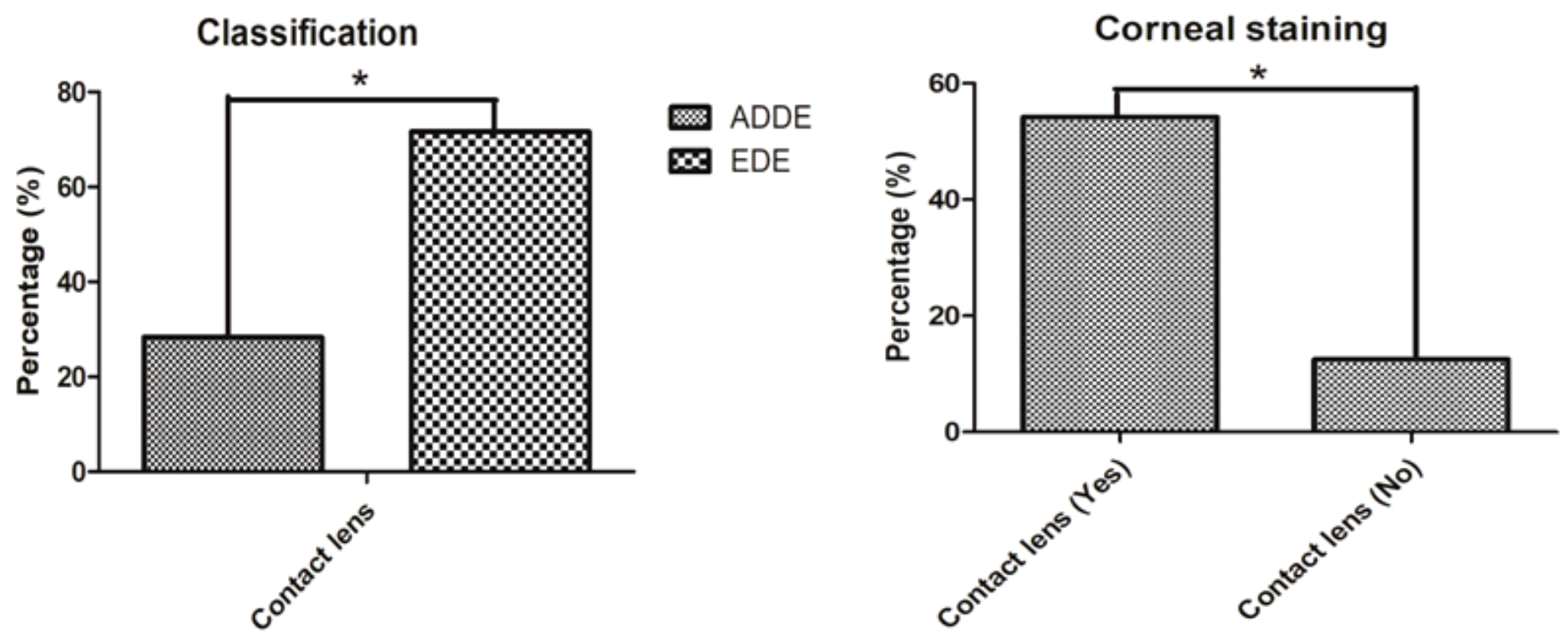

\section{Figure 3}

The effects of contact lens on the classification of DED and corneal staining. According to our data and statistical analysis, we found that corneal contact lens is a leading independent risk factor, not only initiated EDE dry eye, but also act as the primary factor of corneal damage. (A): *: Data of the EDE percentage in the contact lens group versus that in ADDE groups, $P<0.01$. (B): *: Data of the positive corneal staining percentage in the contact lens group versus that in no contact lens groups, $\mathrm{P}<0.01$. Data were analyzed by chi-square test.

A

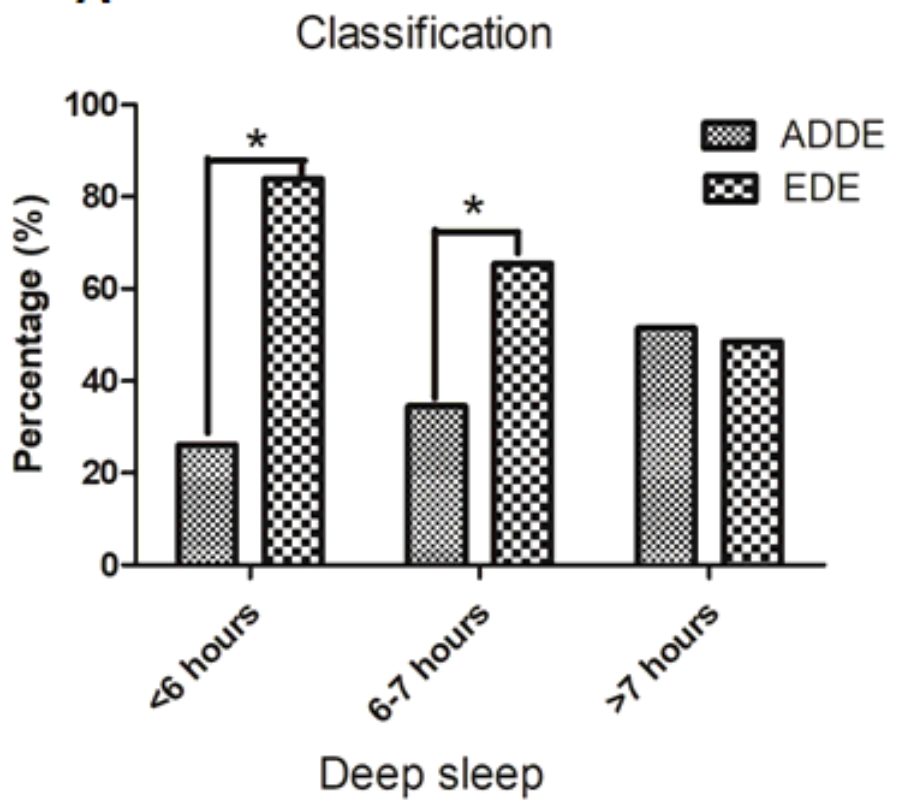

B

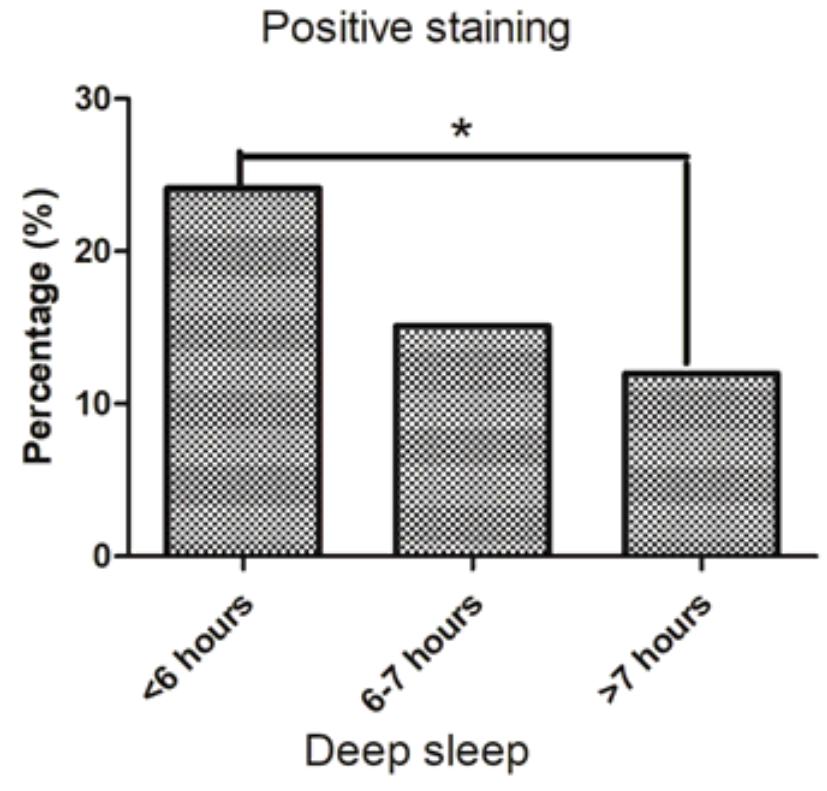

Figure 4

The effects of deep sleep on the classification of DED and corneal staining. Based on the analysis of our collected data, we found that deep sleep time may be a protective factor for EDE and ocular surface lesions. (A): Deep sleep has a significant effect on the proportion of classifications of dry eye. With the increase of deep sleep time, ADDE 
increased significantly, while the incidence of EDE gradually decreased. *: Data statistics of percentage of ADDE versus $E D E, P<0.01$. (B): Deep sleep has a protective role on the ocular surface tissue. With the increase of deep sleep time, the incidence of corneal positive staining also showed a gradual downward trend. *: Data statistics of positive corneal staining incidence in less than 6 hours deep sleep subjects versus that in more than 7 hours deep sleep subjects, $P<0.01$. Data were analyzed by chi-square test.

\section{Supplementary Files}

This is a list of supplementary files associated with this preprint. Click to download.

- Questionnaire.docx 